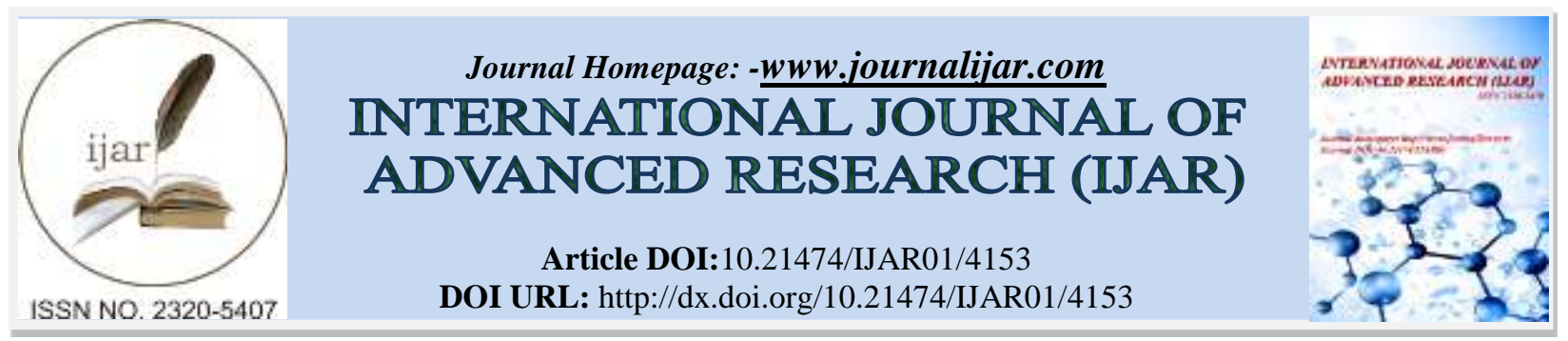

RESEARCH ARTICLE

\title{
ASSESSING THE EFFICACY OF TRAINING AND DEVELOPMENT TECHNIQUES AND ITS EFFECT ON EMPLOYEE'S JOB PERFORMANCE AT BHARAT COKING COAL LIMITED.
}

Oppong Gladys Yaa Saah.

\section{Manuscript Info}

Manuscript History

Received: 13 March 2017

Final Accepted: 16 April 2017

Published: May 2017

Key words:-

TDT (training and development

techniques), BCCL (Bharat Coking

Coal), On-the-Job and Off-the-Job.

\section{Abstract}

Human capital has gained famous attention over the years as the most important asset to every organization. The resultant falls training which is imperative to be rolled by every organization. The quality of human capital depends on the skills possessed which come through training and linear development. The study therefore emphasized on assessing the "efficacy of training and development techniques and its impact on employee's job performance". The study factored Bharat Coking Coal limited which is one of the subsidiaries under Coal India. A sample of 290 respondents from all areas was chosen using snowballing sampling technique. The study adopted a casual survey where the causes and effect of Training and development were analyzed based on the two hypothesis formulated. A questionnaire survey including both open and close ended with Likert 5 point scale used in collecting data from the selected respondents. Data was analyzed using both SPSS version 20 and AMOS version 20.Various analytical tools such as Ordinary Least Square regression, factor analysis and SEM were performed on testing the connection between training \& development and employees job performances. Further to this study, findings revealed that, both On-the-Job as well as Off-TheJob method has significant impact on employee's job performance.

Copy Right, IJAR, 2016,. All rights reserved.

\section{Introduction:-}

In this smart, swift and dynamic competitive business environment, has forced organizations to mature their proficiency of supporting human resource with their business strategy. Value creation which revolves around human development is the need of the hour. Business and its surrounding uncertainties, as organizations comprehend its constraint in combating these challenges and should of course invest and focus much on training programs as a means of enhancing employees to competent enough to face uncertainties to be able to a sustain pressure in the market (Tai, 2006). The survival of every firm in the competitive society is a link between training its employee to show creativity, innovation and inventive to habitually enhance performance which in turn leads to competitive advantage.There is no doubt that, effective training is helpful and has a lot of advantages to firms such as the undoubtable role in developing and retaining capabilities at both the individual and firms context, and thus partakes in the process of every organizational change (Valle et al. 2000). Furthermore, it boosts the retention strength and the capabilities of all talented workforces, which in turn lowers the rate of job rotation of the workers being intentional or unintentional (Shaw et al. 1998). Furthermore, this will increases the employee's motivational level since firms commitment towards its workers will increase and be an assurance to the workers (Pfeffer, 1994). Performance of any organization is determined by its human capital. Human capital materialization takes place 
through right frontrunners and good quality HR practices. It is human capital that institutes the intellectual wealth and enhances the shareholder value. Human capital shows a reflective bearing on the organization performance. Learning at organizational level is more of an attitude, a culture at the workplace. It concerns openness, listening, constant interaction and adaptability. Acquisition, exchange and application of knowledge throughout the organization are an essential part of learning culture and vital to human development and value creation in any organization. Human capital in its distinct nature has is different from all other resources of the firm. It includes the skills of employees, commitment, competencies, loyalty and more precisely motivation and besides other components such as experience and technical expertise. Human capital if nurtured and developed perfectly by an organization, it will drive towards enhancing other assets necessary for organizational growth. For the above declared analysis, this project effort on in-depth study and perilous analysis of HRD and training phases of a public sector undertaking i.e. Bharat Coking Limited, one of the subsidiaries of Coal India.

\section{Objectives:-}

1. Identify the training and development techniques widely adopted by Bharat coking Coal Ltd (BCCL).

2. Establish the impact of training and development technique (On-the-Job) on job performance of Bharat coking employees (BCCL).

3. Establish the effects of training and development technique (Off-the-Job) on job performance of Bharat coking employees (BCCL).

\section{Research Problem:-}

Training, as the panacea to job as well as skills development is one of the learning experiences which improves individual capabilities as it fully focuses on consistent seeks and permanent change which in turn improves employees abilities to perform work or task more effectively. Organizations, irrespective of the industry it falls under, requires the best and qualified workforce to perform the assigned and designated task more effectively in aid of yielding better results. Irrespective of their educational background, consistent training is always necessary since technology, procedures and introduction of new tools are flipping in and out like a book. Most businesses have failed to reach their target leading into low capitalization suggested by Business focus Unit. It's been also evident that, most organizations are still facing weak and less skilled workers especially with the government sector companies making the private organizations outperform the public ones. This is because of lack of consistent employee training as a way of upgrading their skills and creativity. As the paper seeks to evaluate the efficacy of training and its accompanied development and how it impacts on employee's job performance, BCCL as a subsidiary of Coal India Ltd was seen in the red light of low production in recent days. Therefore the paper tried to assess if the resulting problem is from low creativity and obsolete skills of employees. If objective is achieved, it will depict whether training improves employees skills which leads to job performance or not.

\section{Literature Review:-}

The workforce of every frim or organisation is no more considered as physical asset but the intellectual asset of organisation which has been proven as the key to firm's value creation and competitive advantage to firms. Human asset can be interchangeably used as the human staff, organisational manpower, human resource and personal. This emerging trend can be traced from the time when knowledge organisations emerged and the growing power that inherent the human force has been seen as the driver for value in these knowledge driven firms. Even though these assets don't belong to the organisation as it's the knowledge of the individuals but when taken appropriate care, it can exert great impact on the firm's performance and stay competitive in the dynamic changing world of business.

\section{Training and Development Methods:-}

Training methods refer to the means by which learning contents are communicated to learners or trainee. The effectiveness of training depends on the methods and techniques used. However, choice of any method by an organization mostly depends on factors like cost, time availability length number of the required trainees, the depth of knowledge required and the trainee's background. (Adamu; 2008).

In training, the two broad methods that every organization may choose for training and developing the skills as well as the capabilities of its workforce are on the job and off the job. The methods; on-the-job and off-the-job training which can be differentiated by the place where it's being conducted and whether it's done along with the normal task of an employee or not.. Looking at on-the-job training, most of the methods may include job rotations, transfers, mentoring and coaching. However, off-the-job training on the other hand has such as role playing, conferences, vestibule training as explained below. 


\section{On-Job Training:-}

This type of on the job form of training has a distinct feature where training is well planned in a structured form that is done at the normal workstation or works house of the selected trainee. In this type of training, they may be supervisors or site managers who would guide the trainees to help develop the skills of trainees where the time is been pre specified in advance. This type of training is mostly used and given when employees first join the fir or the organisation which serves as a way of introducing the new employed worker to the job specifications and description. The following sets out the various forms under which on the job training could take;

\section{Job rotation/ transfers:-}

According to (McCourt \& Eldridge 2003), it's one of the ways in which organisations develop the skills of their employees for special needed skills to occupy or take a higher position in the organisation. That is whenever an employee's moves higher in rank; it calls for imminent training to enhance the capabilities of such employee to match the required qualities to fit the position. Transfer for example pushes the employee for instance to be familiarised with the culture and nature of work ethics if employee are transferred to a different country.

\section{Apprenticeship:-}

Apprenticeship is known as a system where new generation of practitioners are being trained in a structured form for employees competency based on set of skills. This ranges from those seeking to move from being normal crafting to be masters in their professional work and operation. Apprenticeship training provides an individual with the knowledge and skill in doing a craft or a series of related job (Ezeigbo, 2011). Looking at the nature of this form of training, most often, the form of training is done in a way where the trainee would be working under a master for some period (say 4-6 years) till they achieve measurable competencies which was set before them or their organisation. During the apprenticeship period, the employer pays them allowance for their upkeep. Sometimes, apprenticeship programme combines on the-job training and formal or classroom instruction (Ezeigbo, 2011).

\section{Coaching and mentoring:-}

According to Devanna et al;(1984) coaching or to say monitoring is a way where the experienced workers or managers train and monitor the less experienced ones and this in turn provides a wide spectrum of merits to the organisation vis-à-vis developing the skills of the said trainees to be equipped for every responsibility (Torrington et al. 2005). Most especially, the newly signed up graduates who has little or no working experience are given the chance to be under an experienced worker who will coach and monitor such employee to be fully capable and equipped in his/her skills needed for the under designed task.

\section{Orientation:-}

Every new recruited employee seems to be lost at the moment he/she gets into the organisation. This therefore required a salient guide through the workplace to be familiarised with the organisation and its environment. This form of first time training given is the introductory training which is termed as orientation Din this process, the newly employed workers gets opened and acquainted to how and what their job or task would be, the working physical environment and everything the is a must thing to know. They are then taken through the general overview of the working and physical work place including health and safety issues, working systems, technology, and the layout of their office, organizational culture, , working conditions, processes and procedure.

\section{Internship:-}

Considering this type of on-the-job training technique, which is somehow similar to apprenticeship but usually for professional career development. The major difference is that internship is typically for college or university students and post-graduate adults go on internship. Generally, this form of training serves as an exchange program where the intern learns from the designed presentations congruent to his career skills. Internship could also be used to decide if a person has interest in a certain career where it may take the form of paid, partial or unpaid internships. However, for paid internships, they are common in professional fields where as Non-governmental and non-profit organizations have unpaid internship.

\section{Special Assignment:-}

This is the form which give the employee the first trial to hand problematic issues which require solutions which in turn provides a medium of enhancing the IQ and problem solving skills of the employee to meet contingent issues in holding managerial positions. More often than not, special assignment is most likely essential when special workers as well as departmental mangers or foreman need to know little idea about the work done at each level, Laird et al, 
(2003). Most of the multinational companies normally embark on this type of training where they could send their employee to work on a special assignment in a different current which could take for like 5-10 weeks.

\section{Off Job Training:-}

Unlike on the job where training is done within the working pace of the employee, off the job takes place somewhere away from the normal working place of the employee. It utilizes some salient modes such as, presentations, simulation, case studies, role playing and lectures

\section{Conferences:-}

This form of training is seen as one of the most efficient and cost reduction technique as it provide training services to large number of trainees or audience which can take lot of trainees depending on the auditorium size. However, it is of no doubt that, with this form of training, its likely most or some of the trainees might to benefit well from it because the larger the size of audience, the likely it impact reduce as not all trainees would be given similar attention and priority as compared to their fellows.

\section{Informal Training: =-}

With informal training, it mostly occurs through the interactions that goes on between lower and senior worker/supervisors which recommends and feedback among employees. Lot of employee's task description is being understood through the informal conversation that they have with their seniors or managers which helps them to get the flow their task operations (Mathis and Jackson, 2004).

\section{E-Learning: On-line training:-}

E-learning is the use of the internet or an organizational intranet to conduct training on-line. As more and more employees use computers and have access to internet portals, their employers look for training opportunities on-line that will be beneficial to the employee. With most supported computer simulations within organizational training can duplicate the psychological and skills that is required to perform some specific task which in way provides trainees with physical resemblances of the working place (Mathis and Jackson, 2004).

\section{Vestibule training:-}

This is a system of training whereby an employee is sent to a replica organization in another location outside his place of work. The training place looks exactly like the employee's work environment. The difference between the training venue and employee's workplace is that emphasis is on learning instead of production. The trainee is there only to acquire the desired knowledge or skill. Some banks in Nigeria have this kind of training facility. The essence is to ensure that the trainee learns the job skills without necessarily imbibing some bad customs and practices of the work environment. Another advantage of this method is that costly mistakes are avoided and acquisition of knowledge is enhanced since the trainee practices with identical equipment and tools.

\section{Materials and Methods:-}

As per Kotzar et al ; (2005), a research methodology can be defined as a format of investigation and how studies are structured which defines the process of focusing on the researcher's idea for achieving the aim of a particular study. This chapter therefore describes the methodology that would be used to carry out this study

\section{Research Design:-}

Research design can take the form of being exploratory; descriptive; and causal and for the benefit of the research questions; this study adopted a causal survey design. This type of research design helps when the research seeks to observe behavior and evaluate the causal and effect of such behavior.

\section{Methodology:-}

The study population included all staffs of Bharat Coking Coal in Dhanbad, a notable coal mining city in Jharkhand. For the purpose of this study, a sample size of 290 was taken from the total working employees as at the time the study was done. This sample involves all head officers as well as all field workers from various areas. Validity, reliability and empirical data were a heart in job target of the research so far as the study question is concerned. There, amongst the entire population that represented the study, the researcher yet selected all staff members using snowballing sampling technique. This sample method was adopted because, working schedules of the staff is very tight ,so in order to reach such huge number, identification of a staff member linked to another staff member and it 
continued like that. In conducting this research, structured questionnaire and structured record reviews of Bharat coking coal were employed. The questionnaires were divided into two parts, that is the open ended questions as well as close ended questions were administered to elicit information from the respondents which was prepared in in both Hindi and English to eliminate language barrier. The questionnaires designed by the researcher for the purpose of the study had three main types of questions which either took the form of five-point scale, multiple choice questions or open ended questions. More so, questions which are on ranking factors were developed using Likert five point rating scale. The data collected from survey questionnaire were carefully analysed using Statistical Package for Social Sciences (SPSS) and Amos, allowing the researcher to present the information in form of tables and figures.

\section{Conceptual Framework:-}

The conceptual model in this study is specified as follows:

$\mathrm{Y}=f(\mathrm{TDT})$

Where $\mathrm{Y}$ is the Job performance of employees;

TDT is the Training and Development Techniques which include On-the-job as well as Off-the-job training techniques.

\section{Results and Discussion:-}

Objective One: Identify the training and development techniques widely adopted by Bharat coking Coal Ltd (BCCL).

SEM approach integrating a series of qualitative and quantitative analysis was used in testing this model. Firstly, the study analyzed measurement model and then structural model and for the construct validity of the items, factor analysis was employed. To reduce large number of variables into a smaller set, varimax rotation test was used. After that the study analyzed measurement model or confirmatory factor analysis by a maximum-likelihood estimation procedure using AMOS version 20. In assessing how fit the model is, Chi- square ( $\chi 2$ ) (Bollen, 1989); comparative fit index, (Bentler, 1990); root mean square residual, (Hu \& Bentler, 1995); and (NFI) (Bentler \& Bonett, 1980 were all used. More so, root mean square error of approximation by (Browne \& Cudeck, 1993) along with other was also used. In testing the significance of the model, t-values greater than 2 were used in doing so (Byrne, 1998).

Generally, for every fit statistics to be a good model, it should be greater than or equal to.90 for both comparative fit index and normed fit index. (Bentler and Bonnet, 1980). More so, values which are lower than 0.08 indicate the model fit under RMSEA and SRMR. The first step identified latent variables in the model using SPSS as an exploratory factor analysis and a principal component with varimax rotation. A minimum eigenvalue of one was used as the criterion to control the number of factors extracted.

Table 1:-Factor analysis results for model constructs.

\begin{tabular}{|c|c|c|c|}
\hline Factors & 1 & 2 & 3 \\
\hline On-the-Job & & & \\
\hline Job rotation & .837 & & \\
\hline Apprenticeship & .721 & & \\
\hline Coaching and monitoring & .785 & & \\
\hline Orientation & .783 & & \\
\hline Internship & .559 & & \\
\hline Special assignments & .666 & .806 & .818 \\
\hline Off-the-Job & & .769 & .792 \\
\hline Conferences & & .737 & \\
\hline Informal training & & & \\
\hline E-learning & & & \\
\hline Vestibule training & & & \\
\hline Role playing & & & \\
\hline Employees' job performance & & & .770 \\
\hline $\begin{array}{c}\text { Impact of training methods on job } \\
\text { performance }\end{array}$ & & & \\
\hline $\begin{array}{l}\text { Relevance of training received on your } \\
\text { work }\end{array}$ & & & \\
\hline
\end{tabular}




\begin{tabular}{|c|c|c|c|}
\hline $\begin{array}{c}\text { Training benefits in identifying for } \\
\text { development }\end{array}$ & & .785 \\
\hline $\begin{array}{c}\text { How training has improved job } \\
\text { performance }\end{array}$ & & & .702 \\
\hline $\begin{array}{c}\text { Rating of quality of training on job } \\
\text { performance }\end{array}$ & & & .865 \\
\hline Cronbach's Alpha & $\mathbf{0 . 8 6 8}$ & $\mathbf{0 . 9 3 5}$ & $\mathbf{0 . 9 1 3}$ \\
\hline
\end{tabular}

\section{Interpretation:-}

Exploratory factor analysis was conducted which resulted in three factors explaining $63 \%$ of the variance. We names three factors as On-the-Job, Off-the-Job and Employees job performance. See table-1. Then the measurement model fit test was done. Since the RMSEA and RMR was more than .05 and .08 , the present measurement model could not fit. Therefore the modification fit index was used to correlate the error terms of the latent constructs to bring the model fitness. The confirmatory factor analysis supported the exploratory factor analysis. Fit measurement model was acceptable as it was $(\chi 2=876.675, \mathrm{NFI}=.952, \mathrm{CFI}=0.969, \mathrm{RMSEA}=0.047$, and $\mathrm{RMR}=0.027)$.

Table 2:- Convergent and discriminant validity

\begin{tabular}{|c|c|c|c|c|c|c|c|}
\hline & 兄 & $\sum_{2}^{1}$ & $\sum_{2}^{\infty}$ & 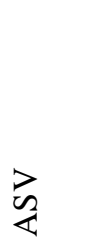 & 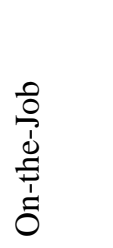 & $\begin{array}{l}\stackrel{0}{0} \\
\stackrel{1}{0} \\
\stackrel{ \pm}{ \pm} \\
\stackrel{ \pm}{0}\end{array}$ & 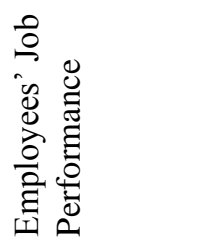 \\
\hline On-the-Job & 0.936 & 0.831 & 0.005 & 0.003 & 0.912 & & \\
\hline Off-the-Job & 0.947 & 0.819 & 0.053 & 0.013 & 0.066 & 0.905 & \\
\hline $\begin{array}{l}\text { Employees'Job } \\
\text { Performance }\end{array}$ & 0.906 & 0.707 & 0.22 & 0.048 & 0.012 & 0.231 & 0.841 \\
\hline
\end{tabular}

Hair et.al; (2010) suggest that while doing CFA, convergent and discriminant validity which are considered as subcategories or subtypes of construct validity, should be conducted to establish construct validity and reliability. They also suggest criteria for acceptance of convergent and discriminant validity. They are as follows:

"Reliability" using Composite Reliability > 0.7;

"Convergent Validity" using (Average Variance Extracted) $>0.5$;

"Discriminant Validity" using (Maximum Shared Variance) < AVE or ASV (Average Variance Extracted) $<$ AVE or Square root of AVE greater than inter-construct correlations.

\section{Interpretation of Results:-}

The results of the analysis are in the table 2. Each research construct conforms to the above four criteria. Thus all necessary indices are acceptable. The construct reliability ranged from 0.936 to 0.906 . And the convergent validity was assessed by average variance extracted (AVE) which was greater than 0.50 for all constructs. Finally, discriminant validity was assessed by Square root of AVE which were greater than inter-construct correlations. This means the indicators have more in common with the construct they are associated with than they do with other constructs.

\section{Hypothesis Testing:-}

H1: On- the-Job training technique has a significant impact on employee's job performance.

H2: Off-the-Job training technique has a significant impact on employee's job performance.

\section{Structural Model:-}

Structural Equation Modeling (SEM) was applied to estimate the structural model or the path analysis. Apart from the chi-square statistic $\left(\chi^{2}=944.23, \mathrm{p}<0.001\right)$, all fit indices showed a good fit with the data $(\mathrm{NFI}=0.95$, CFI=0.96, RMSEA=0.053, RMR=0.49). Even the present study fulfilled the criteria of adequate sample size (i.e. $\mathrm{n}>290$ ). Table-3 below shows the results of the structural model analysis as well as significant standardized path coefficients and t-values. 
Table 3:-Test Results: path coefficients.

\begin{tabular}{|l|l|l|l|l|l|}
\hline Hypothesis & Regression Weights & $\begin{array}{l}\text { Standard } \\
\text { Coefficient } \\
\text { Estimates }\end{array}$ & t value & $\begin{array}{l}\text { P } \\
\text { value }\end{array}$ & Results \\
\hline H1. & On-the-Job & .699 & 25.385 & $* * *$ & Supported \\
\hline H2. & Off-the-Job & .256 & 9.318 & $* * *$ & Supported \\
\hline
\end{tabular}

\section{Interpretation:-}

From the analysis, it should be noted that both the factors have shown positive influence on employee's job performance. The results have been shown in the table-3, i.e., On-the-Job $(\beta=.699, p<0.05)$, Off-the-Job ( $\beta=.256$, $\mathrm{p}<0.05)$. Per the above results, the entire proposed hypothesis was fully supported. Furthermore, a focal point on the $\mathrm{R}^{2}$ value, in which in the conceptual model which was proposed earlier in this research showed a significant amount of variance for employee's job performance $\left(\mathrm{R}^{2}=.702\right)$.

Table 4:- Provides the full description of the coefficients for the significant variables in the regression model.

Table 4:- Regression model

\begin{tabular}{|c|c|c|c|c|c|c|}
\hline Parameters & \multicolumn{2}{|c|}{ Unstandardized Coefficients } & & \multicolumn{2}{c|}{ Co-Linearity Statistics } \\
\hline Variables & $\mathrm{B}$ & Std. Error & t-value & Significance & Tolerance & VIF \\
\hline (Constant) & .739 & .380 & 1.945 & 9 & & \\
\hline Job Rotation And Transfer & .730 & .071 & 10.244 & .000 & .298 & 3.358 \\
\hline Apprenticeship & .756 & .060 & 9.892 & .000 & .208 & 3.470 \\
\hline Coaching And Monitoring & .642 & .072 & 7.589 & .001 & .396 & 2.523 \\
\hline Orientation & .411 & .056 & 6.446 & .003 & .349 & 2.864 \\
\hline Internship & .404 & .057 & 5.670 & .014 & .486 & 3.271 \\
\hline Special Assignments & .418 & .065 & 7.923 & .047 & .696 & 1.436 \\
\hline Conferences & .305 & .071 & 6.069 & .045 & .366 & 2.731 \\
\hline Informal Training & .428 & .055 & 5.514 & .039 & .455 & 2.198 \\
\hline E-Learning & .337 & .064 & 5.586 & .030 & .424 & 2.358 \\
\hline Vestibule Training & .702 & .058 & 10.036 & .001 & .296 & 3.018 \\
\hline Role Playing & .601 & .060 & 9.022 & .002 & .341 & 3.561 \\
\hline Model fitness & $\mathrm{F}=40.532$ & & & & & \\
\hline & $\mathrm{Adj} . \mathrm{R}^{2}=.601$ & & & & & \\
\hline
\end{tabular}

\section{Interpretation:-}

With this, OLS linear regression was configured with On-the-Job (Job Rotation and Transfer, Apprenticeship, Coaching and monitoring, Orientation, Internship and Special Assignments) ,Off-the-Job (Conferences, Informal Training, E-Learning, Vestibule, Role Playing Training ), as independent variables and Employee's Job Performance as dependent variable for measuring the effect of training and development program on employee's performance in the organization.

The overall regression model explained substantial part of the variance with adjusted $\mathrm{R}^{2}=.601$ and $\mathrm{R}=.785$. Further, in ANOVA test, the study finds the model significant $(\mathrm{F}=40.532, \mathrm{P}<.001)$, hence this shows that linear relationship exists among certain variables in the model (in other words $\mathrm{R}^{2} \neq 0$ ). That is both On the- Job and Off the - Job are all significant in employees job performance.

\section{Recommendations:-}

$>$ Based on the result, I recommend employees selection for training based on favoritism should be discouraged by the management even though there was no evident case of that sort, however, it's been advised that all department at BCCL shouldn't embark on favoritism in selection of trainees.

$>$ HR department should ensure also that adequate training design, rich in content is used for employee training. The content should be able to include all the identified skill gaps, while making sure that a trainer who is knowledgeable and experienced in that area is contracted for the training delivery.

$>$ Adequate review mechanisms for gaining the effectiveness and relevance of training programs should be developed. 


\section{Conclusion:-}

This paper assessed the efficacy of training and development techniques on BCCL employee's job performance. Across the sample of 290 respondents that were chosen for the study through snowballing sampling, all 11 categories of TDT's surveyed (Job Rotation and Transfer, Apprenticeship, Coaching and monitoring, Orientation, Internship and Special Assignments, Conferences, Informal Training, E-Learning, Vestibule, Role Playing Training), are adopted by the all the selected respondents for the study. Further, the results also revealed that, respondents have gone through some form of training, which has in turn given them in-depth knowledge of the roles they are to perform. Neither is it evaluated to ensure whether the training has had the desired impact. The OLS regression analysis proved positively showing that, all training and development methods has one way or the other impacted on the performance of the employees who were chosen for the purpose of this study. Closing up, the study can therefore conclude that, training is an important tool in developing employee's capabilities and skills which can easily have salient significant impacts on their job performance.

\section{Reference:-}

1. Adamu, S. (2008), Manpower Planning and Administration, Lagos: National Open University of Nigeria.

2. Bentler, P. M. (1990). Comparative fit indexes in structural models. Psychological bulletin, 107(2), 238.

3. Bentler, P. M., \& Bonett, D. G. (1980). Significance tests and goodness of fit in the analysis of covariance structures. Psychological bulletin, 88(3), 588.

4. Bentler, P.M. and Bonnet, D.C. (1980), "Significance Tests and Goodness of Fit in the

5. Bollen, K. A. (1989). A new incremental fit index for general structural equation models. Sociological Methods \& Research, 17(3), 303-316.

6. Bourne, M. (2004). Driving value through strategic planning and budgeting. A report on the Better Budgeting forum from CIMA and ICAEW. CIMA.

7. Browne, M. W., \& Cudeck, R. (1993). Alternative ways of assessing model fit. Sage focus editions, 154, 136 136.

8. Byrne, D. S. (1998). Complexity theory and the social sciences: an introduction. Psychology Press.

9. Devanna, M. A., Fombrun, C. J., and Tichy, N. M. (1984). A framework for strategic human resource management. In Fombrun, C.J., Tichy, N.M. and Devanna, M.A. (Eds.), Strategic human resource management (33-55). New York, NY: Wiley.

10. Ezigbo, C.A. (2011), Advanced Management: Theory and Applications, Enugu: Immaculate Publications Limited.

11. Hair Jr, J. F., Black, W. C., Babin, B. J., Anderson, R. E., \& Tatham, R. L. (2010). SEM: An introduction. Multivariate data analysis: A global perspective, 629-686.

12. Hair, J.F.J., Money, A.H., Samuel, P. and Page, M. (2010). Research Methods for Business. U.S: Wiley.

13. Kotzar, H., Seuring, S., Muller, M. \& Reiner, G. 2005: Research methodologies in supply chain management, Yhysica-Verlag, Germany: Heidelberg.

14. Laird, D., Holton, E. F., \& Naquin, S. (2003). Approaches to training and development: revised and updated. Basic Books.

15. MacCallum, R. C., Browne, M. W., \& Sugawara, H. M. (1996). Power analysis and determination of sample size for covariance structure modeling. Psychological methods, 1(2), 130.

16. Mathis, R.L. and Jackson, J.H. (2004), Human Resource Management (10th ed), Singapore: South-Western.

17. McCourt, W., \& Eldridge, D. (2003). Global human resource management: managing people in developing and transitional countries. Edward Elgar Publishing.

18. Pfeffer, J. (1994). Competitive advantage through people. California management review, 36(2), 9-28.

19. Shaw, J. D., Delery, J. E., Jenkins, G. D., \& Gupta, N. (1998). An organization-level analysis of voluntary and involuntary turnover. Academy of management journal, 41(5), 511-525.

20. Tai, W. T. (2006). Effects of training framing, general self-efficacy and training motivation on trainees' training effectiveness. Personnel Review, 35(1), 51-65.

21. Torrington, D., Hall, L., \& Taylor, S. (2005). Ethics and corporate social responsibility. Human Resource Management, 6th edh, Upper Saddle River, NJ: Prentice Hall, 731.

22. Valle, R., Martin, F., Romero, P. M., \& Dolan, S. L. (2000). Business strategy, work processes and human resource training: are they congruent. Journal of organizational behavior, 283-297. 